\title{
PAROXYSMS OF PALPITATIONS AND VENTRICULAR TACHYCARDIA IN A YOUNG ADULT PRESENTING TO ER- IT CAN BE EBSTEIN'S ANOMALY
}

\author{
Ravindra S. Giri' ${ }^{1}$ Mukkaram Iqbal2, Furquan Inamdar ${ }^{3}$
}

1 Professor, Department of Anaesthesiology, Mahadevappa Rampure Medical College and Research Centre, Kalaburagi. ${ }^{2}$ Assistant Professor, Department of Anaesthesiology, Mahadevappa Rampure Medical College and Research Centre, Kalaburagi. ${ }^{3}$ Postgraduate, Department of Anaesthesiology, Mahadevappa Rampure Medical College and Research Centre, Kalaburagi.

\begin{abstract}
Ebstein's anomaly is a congenital malformation of the heart characterised by apical displacement of the septal and posterior tricuspid valve leading to atrialisation of the right ventricle with a variable degree of malformation and displacement of the anterior leaflet, clinically wide spectrum of presentation is present in anomaly ranging from CCF in neonates to asymptomatic adults where it is detected incidentally. Here we present a c/o 17-year-old male patient, a labourer by occupation, presented to ER with sudden onset of palpitations and dizziness. O/E patient was conscious and obeying commands. PR > 180/min and BP 70 systolic. Treatment was started immediately in the Emergency Room (ER) beginning with oxygen supplementation by face mask at $6 \mathrm{~L} / \mathrm{min}$ and IV line was secured; $1000 \mathrm{~mL}$ of ns bolus infused, vitals remained same. ECG showed ventricular tachycardia. Patient was sedated with 50 mics fentanyl and immediate electrical cardioversion was performed with 100J biphasic. Once ECG changes remained refractory, 200j shock given. ECG rhythm reverted to normal sinus rhythm. The patient was later diagnosed to have Ebstein's anomaly on performing 2D echo.
\end{abstract}

\section{KEYWORDS}

Palpitations, Ebstein's Anomaly, Ventricular Tachycardia.

HOW TO CITE THIS ARTICLE: Giri RS, Iqbal M, Inamdar F. Paroxysms of palpitations and ventricular tachycardia in a young adult presenting to ER - it can be Ebstein's anomaly. J. Evolution Med. Dent. Sci. 2016;5(86):6435-6436, DOI: 10.14260/Jemds/2016/1456

\section{BACKGROUND}

Ebstein's anomaly is a congenital malformation of the heart that is characterised by apical displacement of the septal and posterior tricuspid valve leaflets leading to atrialisation of the right ventricle with a variable degree of malformation and displacement of the anterior leaflet.

Wilhelm Ebstein first described a patient with cardiac defects typical of Ebstein's anomaly in 1866. In 1927, Alfred Arnstein suggested the name Ebstein's anomaly for these defects. In 1937, Yates and Shapiro described the first case of the anomaly with associated radiographic and electrocardiographic data.(1)

\section{CASE PRESENTATION}

Here we present a case of 17-year-old male patient, a labourer by occupation, who presented to emergency room with complaints of sudden onset of palpitations and dizziness since last $6 \mathrm{hrs}$. It was also associated with grade IV breathlessness. On examination, his pulse rate was $>180 / \mathrm{min}$ feeble, BP 70 systolic. Treatment was started immediately in the Emergency Room (ER) beginning with oxygen supplementation by face mask at $6 \mathrm{~L} / \mathrm{min}$ and IV line was secured; $1000 \mathrm{~mL}$ of $0.9 \%$ saline bolus infused, vitals remained same. ECG showed ventricular tachycardia. Patient was sedated with 50 mics fentanyl and immediate electrical cardioversion was performed with 100J biphasic. Once ECG changes remained same 200j shock given,

Financial or Other, Competing Interest: None.

Submission 12-11-2015, Peer Review 08-10-2016,

Acceptance 20-10-2016, Published 27-10-2016.

Corresponding Author:

Dr. Ravindra S. Giri

H. No. 2-909/67149,

Swastik Nagar,

Kalaburgi-585104.

E-mail: mdfurquan16@gmail.com

DOI: $10.14260 /$ jemds $/ 2016 / 1456$

(c) (i) $\Theta$
ECG rhythm reverted to normal. Post procedure his vitals were PR 100/min, BP 100/60 $\mathrm{mmHg}$, maintenance dose of amiodarone started.

After stabilisation in the ER, he was shifted to cardiac ICU. Bed side 2D echo showed atrialisation of the right ventricle with tricuspid regurgitation suggesting Ebstein's anomaly. No clot/thrombus located in any of the cardiac chambers and no septal defect was noticed.

Later, he was managed conservatively in cardiac ICU with T. Amiodarone $200 \mathrm{mg}$ BD and Clopidogrel $75 \mathrm{mg} 1$ OD.

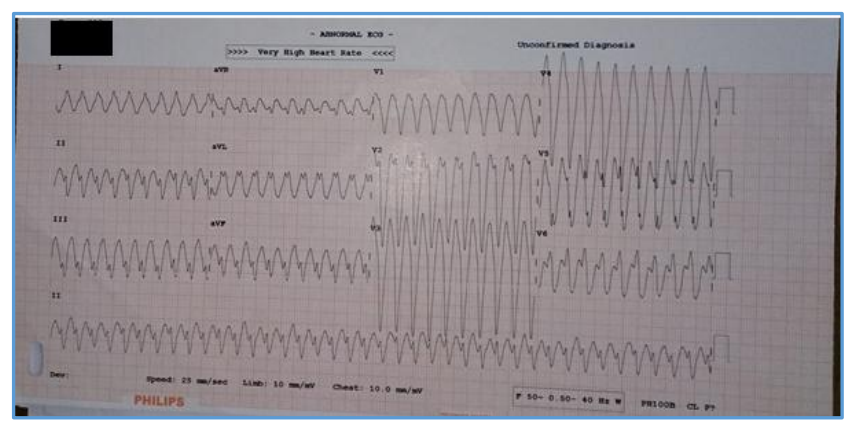

Figure. 1

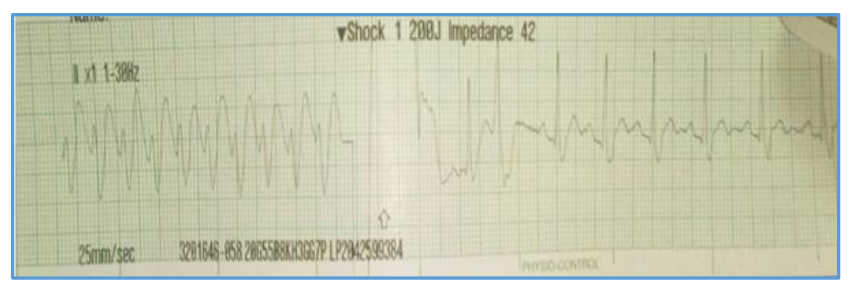

Figure. 2 


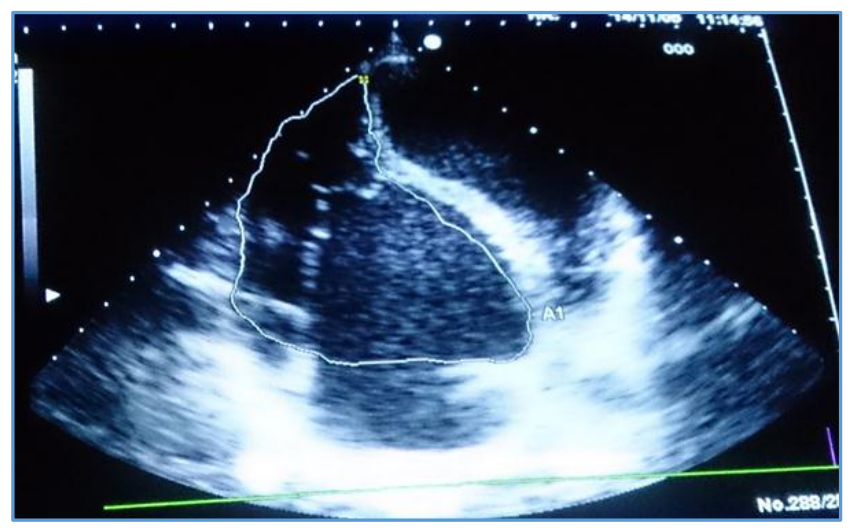

Figure. 3

\section{DISCUSSION}

\section{Signs and Symptoms}

The severity of the haemodynamic derangements in patients with Ebstein's anomaly depends on the degree of displacement and the functional status of the tricuspid valve leaflets. As a result, the clinical presentation of Ebstein's anomaly varies from congestive heart failure in neonates to the absence of symptoms in adults in whom the anomaly is discovered incidentally. Neonates often manifest cyanosis and congestive heart failure that worsens after the ductus arteriosus closes, thereby decreasing pulmonary blood flow. Older children with Ebstein's anomaly may be diagnosed because of an incidental murmur, whereas adolescents and adults are likely to present with supraventricular dysrhythmias that lead to congestive heart failure, worsening cyanosis and occasional syncope. Patients with Ebstein's anomaly and an interatrial communication are at risk of paradoxical embolisation, brain abscess, congestive heart failure and sudden death.

The severity of cyanosis depends on the magnitude of the right-to-left shunt. A systolic murmur caused by tricuspid regurgitation is usually present at the left lower sternal border. Hepatomegaly resulting from passive hepatic congestion due to increased right atrial pressures may be present. The ECG is characterised by tall and broad P waves (resembling right bundle branch block) and first-degree atrioventricular heart block is common. Paroxysmal supraventricular and ventricular tachydysrhythmias may occur and as many as $20 \%$ of patients with Ebstein's anomaly have ventricular pre-excitation by way of accessory electrical pathways between the atrium and ventricle (Wolff-ParkinsonWhite syndrome). In patients with severe disease (marked right-to-left shunting and minimal functional right ventricle) marked cardiomegaly is present that is largely due to right atrial enlargement.

Echocardiography is used to assess right atrial dilation, distortion of the tricuspid valve leaflets and the severity of the tricuspid regurgitation or stenosis. The presence and magnitude of interatrial shunting can be determined by colour Doppler imaging studies. Enlargement of the right atrium may be so massive that the apical portions of the lungs are compressed, resulting in restrictive pulmonary disease.

The hazards of pregnancy in parturients with Ebstein's anomaly include deterioration in right ventricular function due to increased blood volume and cardiac output, increased right-to-left shunting and arterial hypoxaemia if an ASD is present and cardiac dysrhythmias. Pregnancy-induced hypertension may result in the development of congestive heart failure in these women.(2)

\section{Treatment}

Treatment of Ebstein's anomaly is based on the prevention of associated complications including antibiotic prophylaxis against infective endocarditis and administration of diuretics and digoxin for management of congestive heart failure. Patients with supraventricular dysrhythmias are treated pharmacologically or with catheter ablation if an accessory pathway is present. In severely ill neonates with Ebstein's anomaly, an arterial shunt from the systemic circulation to the pulmonary circulation is created to increase pulmonary blood flow and thus decrease cyanosis. Further staged procedures to create a univentricular heart (Glenn shunt and Fontan procedure) may also be considered in these cases. Repair or replacement of the tricuspid valve in conjunction with closure of the interatrial communication is recommended for older patients who have severe symptoms despite medical therapy.(3) Complications of surgery to correct Ebstein's anomaly include third-degree atrioventricular heart block, persistence of supraventricular dysrhythmias, residual tricuspid regurgitation after valve repair and prosthetic valve dysfunction when the tricuspid valve is replaced.(4)

\section{CONCLUSION}

Here, we present a rare case of Ebstein's anomaly in asymptomatic young adult with no significant past history presenting as paroxysms of palpitations and ventricular tachycardia to ER, which was successfully managed in our institution.

\section{REFERENCES}

1. Jost ACH, Connolly HM, Edwards WD, et al. Ebstein's anomaly-review of a multifaceted congenital cardiac conditions. Swiss med weekly 2005;135(19-20):269-81.

2. Samantha A, Franco. Congenital heart diseases. Stoeltings anaesthesia and coexisting diseases 48-72.

3. Paranon S, Acar P. Ebstien's anomaly of tricuspid valve: from fetus to adult. Heart 2008;94:237-43.

4. Nussmeier A. Anaesthesia for cardiosurgical procedures. Millers anaesthesia 7 th edn, 1889-1976. 